Patterns of Land Degradation in Drylands 

Eva Nora Mueller • John Wainwright Anthony J. Parsons • Laura Turnbull Editors

\section{Patterns of Land Degradation in Drylands}

Understanding Self-Organised Ecogeomorphic Systems 


\author{
Editors \\ Eva Nora Mueller \\ Institute of Earth and Environmental \\ Science \\ University of Potsdam \\ Potsdam, Germany \\ Anthony J. Parsons \\ Sheffield Centre for International \\ Drylands Research \\ University of Sheffield \\ Sheffield, UK
}

\author{
John Wainwright \\ Department of Geography \\ University of Durham \\ Durham, UK
}

Laura Turnbull

Institute of Hazards, Risk and Resilience

Department of Geography

Durham University

Science Laboratories

Durham, UK

ISBN 978-94-007-5726-4

ISBN 978-94-007-5727-1 (eBook)

DOI 10.1007/978-94-007-5727-1

Springer Dordrecht Heidelberg New York London

Library of Congress Control Number: 2013943458

(c) Springer Science+Business Media Dordrecht 2014

This work is subject to copyright. All rights are reserved by the Publisher, whether the whole or part of the material is concerned, specifically the rights of translation, reprinting, reuse of illustrations, recitation, broadcasting, reproduction on microfilms or in any other physical way, and transmission or information storage and retrieval, electronic adaptation, computer software, or by similar or dissimilar methodology now known or hereafter developed. Exempted from this legal reservation are brief excerpts in connection with reviews or scholarly analysis or material supplied specifically for the purpose of being entered and executed on a computer system, for exclusive use by the purchaser of the work. Duplication of this publication or parts thereof is permitted only under the provisions of the Copyright Law of the Publisher's location, in its current version, and permission for use must always be obtained from Springer. Permissions for use may be obtained through RightsLink at the Copyright Clearance Center. Violations are liable to prosecution under the respective Copyright Law.

The use of general descriptive names, registered names, trademarks, service marks, etc. in this publication does not imply, even in the absence of a specific statement, that such names are exempt from the relevant protective laws and regulations and therefore free for general use.

While the advice and information in this book are believed to be true and accurate at the date of publication, neither the authors nor the editors nor the publisher can accept any legal responsibility for any errors or omissions that may be made. The publisher makes no warranty, express or implied, with respect to the material contained herein.

Cover illustration: Kindly provided by Liz Carabine

Printed on acid-free paper

Springer is part of Springer Science+Business Media (www.springer.com) 


\section{Preface}

This book was initiated through an interdisciplinary ESF Exploratory Workshop 'Self-organized ecogeomorphic systems: confronting models with data for land degradation in drylands' - which was held in Potsdam, Germany, on 7-10 June 2010. The workshop brought together for the first time European scientists working in drylands from multiple communities covering the fields of ecology and landscape ecology, geomorphology, hydrology, agronomy, Earth observation and mathematics to discuss their definitions of land degradation, empirical approaches, questions of corresponding spatial and temporal scales, the importance of self-organization and the application of existing modelling approaches.

During the meeting it became clear that there was a fundamental lack of common ground regarding concepts and methodological approaches between the disciplines. To address this deficiency in understanding land degradation and to provide a basis for future interdisciplinary research on ecogeomorphic systems, we harnessed the expertise of this interdisciplinary group to create this keystone manual.

Individual chapters are multi-authored, integrating research and perspectives from the workshop's participants and several invited experts. As opposed to the usual approach to producing an edited book, we took an editorial decision to select themes that emerged from the workshop and subsequent discussions and invite authors to make short contributions on those themes. We then individually and together integrated the materials produced in order to ensure the consistency and coherence of the chapters. The ordering of the authors names is according to the size of their contribution to the chapters. We would like to thank all the contributors for their full co-operation on the less than usual approach in pulling together this volume in the format we decided on.

The editors would like to thank the European Science Foundation funding scheme for fully supporting the exploratory workshop (Grant reference number EW09-011).

Potsdam, Germany

Durham, UK

Sheffield, UK

Durham, UK
Eva Nora Mueller

John Wainwright

Anthony J. Parsons

Laura Turnbull 



\section{Contents}

1 Land Degradation in Drylands: An Ecogeomorphological Approach

Eva Nora Mueller, John Wainwright, Anthony J. Parsons, and Laura Turnbull

\section{Part I Theory: Linking Process to Pattern}

2 The Study of Land Degradation in Drylands: State of the Art ........

Tamara Hochstrasser, James D.A. Millington,

Vasilios P. Papanastasis, Anthony J. Parsons,

Pier Paolo Roggero, Richard E. Brazier, Joan Estrany,

Almo Farina, and Alan Puttock

3 Resilience, Self-Organization, Complexity and Pattern Formation ...

Florian Jeltsch, Laura Turnbull, Stefania Scarsoglio,

Concepcion L. Alados, Francesc Gallart, Eva Nora Mueller,

Nicolas Barbier, James D.A. Millington, John Wainwright,

Mareike Wieczorek, and Volker Grimm

4 Short-Range Ecogeomorphic Processes in Dryland Systems

Nicolas Barbier, Juan Bellot, Pierre Couteron,

Anthony J. Parsons, and Eva Nora Mueller

5 Long-Range Ecogeomorphic Processes

Artemi Cerdà, Francesc Gallart, Junran Li,

Vasilios P. Papanastasis, Robert R. Parmenter,

Laura Turnbull, Anthony J. Parsons, and John Wainwright

6 Integrating Short- and Long-Range Processes into

Models: The Emergence of Pattern

Kelly K. Caylor, Greg S. Okin, Laura Turnbull,

John Wainwright, Thorsten Wiegand, Trenton E. Franz,

and Anthony J. Parsons 


\section{Part II Methods for Confronting Models with Data}

7 Approaches to Modelling Ecogeomorphic Systems .

Laura Turnbull, Tamara Hochstrasser, Mareike Wieczorek,

Andreas Baas, John Wainwright, Stefania Scarsoglio,

Britta Tietjen, Florian Jeltsch, and Eva Nora Mueller

8 Characterizing Patterns

Pierre Couteron, Philip Hunke, Juan Bellot, Joan Estrany,

Núria Martínez-Carreras, Eva Nora Mueller,

Vasilios P. Papanastasis, Robert R. Parmenter, and John Wainwright

9 Assessment of Patterns in Ecogeomorphic Systems

Nicolas Barbier, Juan Bellot, Pierre Couteron,

Thorsten Wiegand, Volker Grimm, Vincent Deblauwe,

Peter Biro, and Eva Nora Mueller

10 Uncertainty Assessment.

Richard E. Brazier, Tobias Krueger, and John Wainwright

\section{Part III Case Studies}

11 Vegetation Change in the Southwestern USA: Patterns and Processes

Laura Turnbull, John Wainwright, and Sujith Ravi

12 Vegetation Mosaics of Arid Western New South Wales, Australia: Considerations of Their Origin and Persistence.

David L. Dunkerley

13 Case Study of Self-Organized Vegetation Patterning in Dryland Regions of Central Africa

Nicolas Barbier, Pierre Couteron, and Vincent Deblauwe

14 Abandonment of Agricultural Land, Agricultural Policy

and Land Degradation in Mediterranean Europe

Anthony J. Parsons

15 Land Degradation in Drylands: Reëvaluating Pattern-Process Interrelationships and the Role of Ecogeomorphology .

Eva Nora Mueller, John Wainwright, Anthony J. Parsons,

Laura Turnbull, James D.A. Millington,

and Vasilios P. Papanastasis

Index 


\section{Contributors}

Concepcion L. Alados Pyrenean Institute of Ecology, Zaragoza, Spain Andreas Baas Department of Geography, King's College London, London, UK Nicolas Barbier IRD/UMR AMAP, Botany and Computational Plant Architecture, Montpellier, France

Juan Bellot Depto. Ecologia, Universidad de Alicante, Alicante, Spain

Peter Biro Institute of Earth and Environmental Science, University of Potsdam, Potsdam, Germany

Richard E. Brazier Geography, College of Life and Environmental Sciences, University of Exeter, Exeter, UK

Kelly K. Caylor Department of Civil and Environmental Engineering, Princeton University, Princeton, NJ, USA

Artemi Cerdà Department of Geography, University of Valencia, Valencia, Spain

Pierre Couteron IRD/UMR AMAP, Botany and Computational Plant Architecture, Montpellier, France

Vincent Deblauwe IRD/UMR AMAP, Botany and Computational Plant Architecture, Montpellier, France

David L. Dunkerley School of Geography and Environmental Science, Monash University, Melbourne, VIC, Australia

Joan Estrany Department of Earth Sciences, University of the Balearic Islands, Palma de Mallorca, Spain

Almo Farina Instituto di Ecologia e Biologica Ambientale, University of Urbino, Urbino, Italy

Trenton E. Franz Department of Hydrology and Water Resources, University of Arizona, Tucson, AZ, USA 
Francesc Gallart Institute of Earth Sciences, Jaume Almera (CSIC), Barcelona, Spain

Volker Grimm Department of Ecological Modelling, Helmholtz Center for Environmental Research UFZ, Leipzig, Germany

Tamara Hochstrasser School of Biology and Environmental Science, Agriculture \& Food Science Centre, University College Dublin, Belfield, Dublin, Ireland

Philip Hunke Institute of Earth and Environmental Science, University of Potsdam, Potsdam, Germany

Florian Jeltsch Plant Ecology and Nature Conservation, University of Potsdam, Potsdam, Germany

Tobias Krueger School of Environmental Sciences, University of East Anglia, Norwich, UK

Junran Li USDA-ARS Jornada Experimental Range, New Mexico State University, Las Cruces, NM, USA

Núria Martínez-Carreras Département Environnement et Agro-biotechnologies, Centre de Recherche Public - Gabriel Lippmann, Belvaux, Luxembourg

James D.A. Millington Department of Geography, King's College London, London, UK

Eva Nora Mueller Institute of Earth and Environmental Science, University of Potsdam, Potsdam, Germany

Greg S. Okin Department of Geography, University of California, Los Angeles, CA, USA

Vasilios P. Papanastasis Laboratory of Range Ecology, Aristotle University, Thessaloniki, Greece

Robert R. Parmenter Valles Caldera National Preserve, Jemez Springs, NM, USA Anthony J. Parsons Sheffield Centre for International Drylands Research, University of Sheffield, Sheffield, UK

Alan Puttock College of Life and Environmental Sciences, University of Exeter, Exeter, UK

Sujith Ravi Department of Environmental Earth System Science, Stanford University, Stanford, CA, USA

Pier Paolo Roggero Desertification Research Centre and Dipartimento di Agraria, Desertification Research Centre and Dipartimento di Agraria, Sassari, Italy

Stefania Scarsoglio Dipartimento di Idraulica, Trasporti ed Infrastrutture Civili, University of Turin, Torino, Italy

Britta Tietjen Institute of Biology, Freie Universität Berlin, Berlin, Germany 
Laura Turnbull Institute of Hazards, Risk and Resilience, Department of Geography, Durham University, Science Laboratories, Durham, UK

John Wainwright Department of Geography, University of Durham, Durham, UK Mareike Wieczorek Department of Geosciences, Alfred Wegener Institute for Polar and Marine Research, Potsdam, Germany

Thorsten Wiegand Department of Ecological Modelling, Helmholtz Centre for Environmental Research UFZ, Leipzig, Germany 